\title{
Leisure therapy: Exploring leisure- specific goals and outcomes in a spinal cord injury rehabilitation unit
}

\author{
Kate E Martin, Ruth J Cox, Melissa B Kendall, Glenda L Price
}

\author{
Kate E Martin \\ Spinal Injuries Unit, Queensland Spinal \\ Cord Injuries Service, Occupational Therapy \\ Department, Princess Alexandra Hospital, Metro \\ South Health, Brisbane, Australia \\ Ruth J Cox \\ Occupational Therapy Department, Princess \\ Alexandra Hospital, Metro South Health, \\ Brisbane, Australia \\ Melissa B Kendall \\ Transitional Rehabilitation Program, Queensland \\ Spinal Cord Injuries Service, Princess Alexandra \\ Hospital, Metro South Health; School of Human \\ Services and Social Work, Griffith University, \\ Logan Campus, Brisbane, Australia \\ Glenda L Price \\ Spinal Injuries Unit, Queensland Spinal \\ Cord Injuries Service, Occupational Therapy \\ Department, Princess Alexandra Hospital, Metro \\ South Health, Brisbane, Australia \\ Correspondence to: Kate Martin \\ Email: kate.martin2@health.qld.gov.au
}

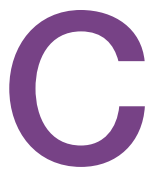

urrent literature suggests that spinal cord injury (SCI) results in decreased participation in many life roles, including work, social activities and leisure pursuits; consequently reducing overall quality of life (Schönherr et al, 2005; Barker et al, 2009; Gassaway et al, 2011). A growing body of literature indicates that participation in leisure activities post SCI is associated with better physical fitness, health and subjective wellbeing (Schönherr et al, 2005; Martin Ginis et al, 2010; Lundstrom et al, 2014). A review by Williams et al (2014) found that leisure involvement and goal attainment enhanced psychological wellbeing through improvements in outlook (Semerjian et al, 2005), post-traumatic growth (Chun and Lee, 2010) and finding purpose in life (Stephens et al, 2012). These bodies of research provide further support to Loy and colleagues' (2003) assertion that the development of skills to effectively manage leisure becomes critical in the community reintegration process, especially for those at risk of poor social and psychological adjustment after a SCI.

Of significance, return to work rates around the world following a SCI have been found to vary between $31 \%$ and $48 \%$ (Schönherr et al, 2005) and people with a SCI have been found to spend on average 2.7 hours less each day in paid work than their able-bodied counterparts (Barclay et al, 2011). Subsequently, participation in non-vocational activities may be more important for the many people who cannot return to work post SCI (Lee and McCormick, 2004; Schönherr et al, 2005; Gassaway et al, 2011) and this may be why leisure involvement has been identified among the top 10 most common problems cited by people with a SCI (Rubinelli et al, 2016).

Greater participation in leisure, skill, and community activities during rehabilitation has been found to be predictive of more participation in active leisure and community-based activities. In addition, less rehospitalisation and pressure area development at 1 year following discharge (Cahow et al, 2012) highlights the need for early inpatient attention to leisure needs. An emphasis on leisure-related goal attainment should therefore be a key focus for SCI rehabilitation programmes.

A leisure therapist is uniquely placed to provide this focus on leisure-related goal attainment in SCI rehabilitation, having obtained a university degree and being trained to work with individuals to recreate their unique leisure lifestyle via a therapeutic recreation programme. (Note: the term therapeutic recreation specialist is usually used worldwide, but in Australia specifically, the term leisure therapist is used and so will be the term used throughout the paper.) According to Gassaway et al (2011), the role of a leisure therapist includes individualised assessment and intervention, patient and family group work, and participation in interdisciplinary conferences. The value of therapeutic recreation provided by a leisure therapist was recognised by the team at an inpatient Spinal Injuries Unit (SIU) in Australia and an appointment to this position was made in 2011.

As part of the multidisciplinary team, the leisure therapist works with people with a SCI and their families to set individualised and measurable goals. Patients' active involvement in goal-setting increases their motivation, participation and satisfaction regarding rehabilitation (Byrnes et al, 2012; Stevens et al, 2013). Although there is literature describing the benefits of leisure involvement, this literature tends to exclude broader leisure pursuits, and focuses more specifically on the physical activity components of leisure (leisure time physical activity) as reported by Ginis et al, 2010). Little has been written about the process or effectiveness of therapeutic recreation programmes in SCI rehabilitation (Gassaway et al, 2011), especially in the inpatient setting. It has also been suggested by Barclay et al (2011) that a greater understanding of the personal meaning and experience of leisure needs may focus interventions to more effectively support individuals following a SCI.

Thus, the aims of this study were to:

- Identify the range of leisure therapy goals nominated by individuals with spinal cord injury in the inpatient setting

- Evaluate the provision of leisure therapy services within the inpatient SIU by gauging individuals' perceptions of their 
performance and satisfaction in terms of leisure-specific goal attainment

- Further explore the sensitivity and applicability of the multidisciplinary goal attainment measure (MGAM) to measure goal attainment in an inpatient multidisciplinary setting.

\section{METHODS}

\section{Study ethics, setting and participants}

The study was approved by the Metro South Hospital and Health Service Human Research Ethics Committee (HREC/12/ QPAH/524) and included inpatients of a SIU in Australia between November 2012 and July 2015. The 40-bed SIU is the only SCI rehabilitation unit in that state, and utilises a client-centred, goalbased framework. The study included adult inpatients ( $>18$ years) of the SIU who had three or more leisure-specific goals. However, these criteria were modified 1 year into the study to include patients with two or more leisure-specific goals in order to maximise inclusion of participants.

\section{Intervention}

A leisure therapist was appointed on a full-time basis to provide goal-directed and client-centred therapeutic recreation services to assist people with a SCI to achieve their leisure-related rehabilitation goals. Interventions included leisure counselling, leisure education, leisure advocacy, leisure modification, leisurebased community integration and leisure management. Table 1 illustrates the range of services that were provided.

\section{Data collection and instruments}

Data was collected longitudinally pre and post leisure therapy service provision. Data was collected using the MGAM (Kendall and Wallace, 2016), which is based on the measurement model offered by the Canadian Occupational Performance Measure (COPM), an occupational therapy specific measure (Law et al, 1990). The COPM was developed to detect change in an individual's self-perception of occupational performance, which is defined as the activities an individual performs in the areas of self-care, productivity and leisure, in the context of their environment (Donnelly, 2004). Professionals reported that the COPM had facilitated improved client participation during rehabilitation (Gustafsson et al, 2012).

The MGAM has been used for over 10 years by the transitional rehabilitation service associated with the SIU in this study. The MGAM offers a viable and valid measure of goal attainment in the multidisciplinary context, indicating relevance to the current study (Kendall and Wallace, 2016).

Using the MGAM, participants nominate two or more leisure-specific goals and rate their performance and satisfaction for each goal. Performance and satisfaction are measured on a scale of 0 to 10 , with 0 being the lowest possible score and 10 being the highest. Initial scoring was conducted following goal identification (pre intervention) with final scoring completed at the point of the participant's perceived attainment of each goal or upon discharge from the SIU.

\section{Statistical analyses}

Statistical analysis was undertaken using PSPP (Version 0.8.5) (GNU Project, 2015). Descriptive analysis of the data identified distributions that approximated normality and therefore data were considered suitable for parametric analysis. Paired samples t-tests were used to examine whether significant change occurred from pre to post on MGAM performance and MGAM satisfaction.

Independent samples t-tests were used to explore differences across demographic variables on the dependent variables of pre, post and change scores for MGAM performance and MGAM satisfaction as well as length of leisure therapy treatment. The level of significance for all analyses was set at 0.01 to allow for multiple comparisons.

Table 1. Leisure Therapy Practice Domains (Queensland Leisure Therapy Network, 2015)

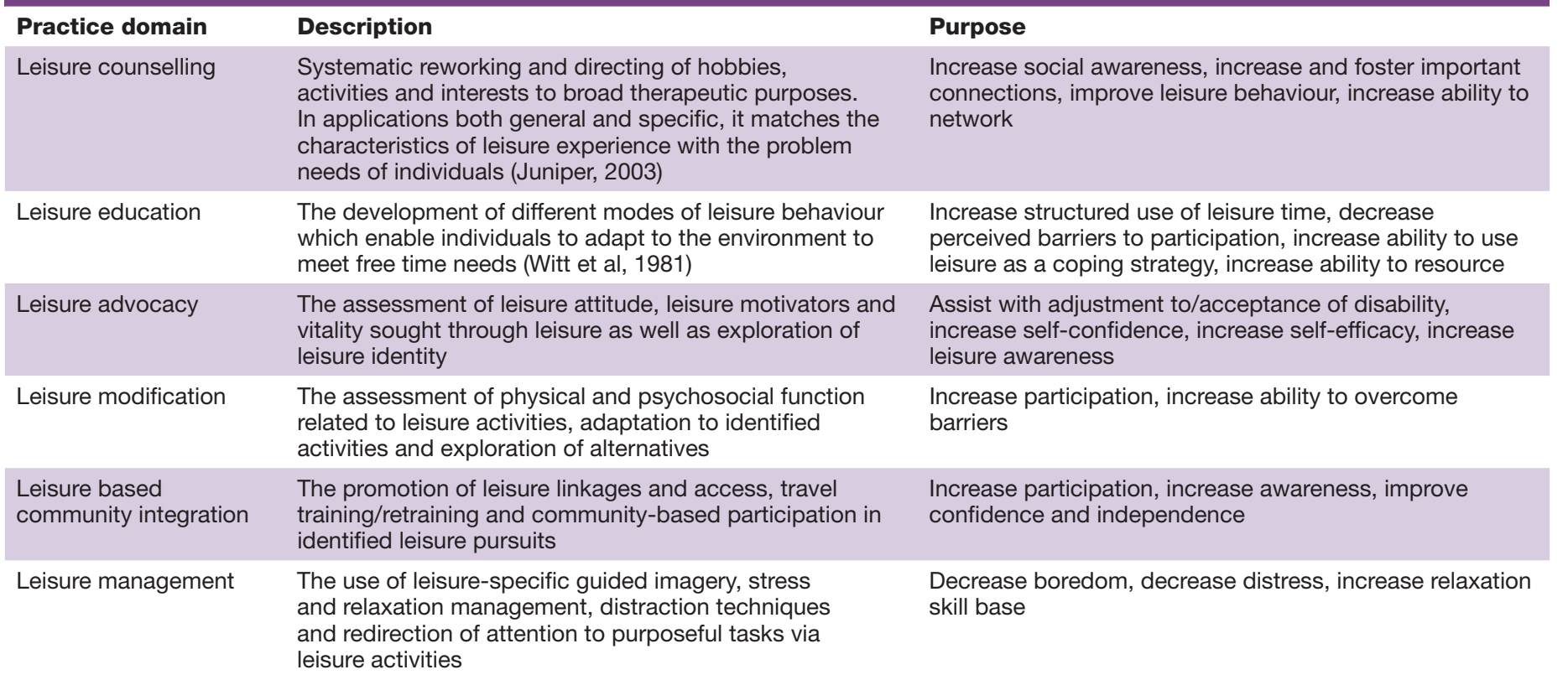




\section{RESULTS}

There were 25 individuals who participated in the present study. Demographic details of these individuals are provided in Table 2. Annual data for the SIU over the 5 years from 2009/2010 to 2013/2014 suggest that the current sample is comparative to the target population. There were a slightly larger percentage of females, those with non-traumatic injuries and tetraplegia level injuries in the current sample as well as slightly more individuals under 40 years of age.

The 25 individuals who participated identified a total of 78 leisure goals (between two and five goals per participant with a mode of three goals per participant). The goals ranged from indoor hobbies and sports, to outdoor hobbies and sports, community access and technology and communication. Table 3 highlights the frequency of goals and examples. In terms of the International Classification of Functioning (ICF) (WHO, 2001), all goals were related to participation.

Table 4 highlights the range, mean, standard deviation and standard error of the mean for MGAM performance and satisfaction scores. There were significant differences between pre and post MGAM performance $(\mathrm{t}=-15.09, P<0.001)$ and satisfaction ( $\mathrm{t}=-13.05, P<0.001)$ scores.

There were no significant differences across gender (male vs female), age (under 40 vs 40 and older), location (metropolitan vs regional/rural), marital status (single vs partnered), cause of injury (trauma vs non-trauma), level of injury (cervical vs thoracic/lumbar) or completeness of injury (American Spinal Injury Association Impairment Scale [AIS] A vs AIS B, C, or D) on pre, post or change scores for MGAM performance or MGAM satisfaction.

In terms of the provision of leisure therapy interventions for participants, a mean of 36.82 (standard deviation [SD] 27.79) hours were spent with the leisure therapist and this ranged between 5.2 hours and 122 hours in total. The total length of hospital stay for participants ranged from 37 to 346 days, with a mean of 183.3 (SD 88.26). There were no differences across gender, age, location, marital status, cause of injury, level of injury or completeness of injury on any of these variables.
Table 2. Sample demographics $(n=25)$ and annual target population averages (2009-2014)

Demographic

Current sample

$n(\%)$

Target population (2009-2014)

\begin{tabular}{|c|c|c|c|}
\hline \multirow[t]{2}{*}{ Gender } & Male & $16(64)$ & $74.2 \%$ male \\
\hline & Female & $9(36)$ & $25.8 \%$ female \\
\hline \multirow[t]{5}{*}{ Cause of injury } & Medical (non-trauma) & $10(40)$ & $36.1 \%$ non-trauma \\
\hline & $\begin{array}{l}\text { Motor vehicle accident/ } \\
\text { motorbike accident } \\
\text { (trauma) }\end{array}$ & $3(12)$ & $63.9 \%$ trauma \\
\hline & Fall (trauma) & $5(20)$ & \\
\hline & Sport (trauma) & $3(12)$ & \\
\hline & Diving/surfing (trauma) & $4(16)$ & \\
\hline \multirow[t]{4}{*}{ Level of injury } & C4 or higher (tetraplegia) & $10(40)$ & $47.1 \%$ tetraplegia \\
\hline & C5-C7 (tetraplegia) & $5(20)$ & \\
\hline & T1-T8 (paraplegia) & $6(24)$ & $52.9 \%$ paraplegia \\
\hline & T9 and below (paraplegia) & $4(16)$ & \\
\hline \multirow{4}{*}{$\begin{array}{l}\text { American } \\
\text { Spinal Injury } \\
\text { Association } \\
\text { Impairment } \\
\text { Scale (at time } \\
\text { of referral) }\end{array}$} & A (complete) & $10(40)$ & $38.0 \%$ complete \\
\hline & B (incomplete) & $4(16)$ & $62.0 \%$ incomplete \\
\hline & C (incomplete) & $5(20)$ & \\
\hline & D (incomplete) & $6(24)$ & \\
\hline \multirow[t]{2}{*}{ Age (years) } & Mean (standard deviation) & $44.46(18.02)$ & \\
\hline & Range & $19-75$ & \\
\hline \multirow[t]{2}{*}{ Age groups } & Under 40 years & $12(48)$ & $43.9 \%$ under 40 years \\
\hline & 40 and older & $13(52)$ & $56.1 \% 40$ and older \\
\hline \multirow{2}{*}{$\begin{array}{l}\text { Time since } \\
\text { injury (days) }\end{array}$} & Mean (standard deviation) & $67.21(48.35)$ & \\
\hline & Range & $17-197$ & \\
\hline \multirow[t]{2}{*}{ Location } & Metropolitan & 14 & \\
\hline & Regional/rural & 11 & \\
\hline \multirow[t]{2}{*}{ Marital status } & Single & 14 & \\
\hline & Married/defacto & 11 & \\
\hline
\end{tabular}

\section{Table 3: Types of leisure goals $(n=78)$}

\begin{tabular}{|c|c|c|}
\hline Type of goal & $\begin{array}{l}\text { Frequency } \\
n(\%)\end{array}$ & Examples \\
\hline \multirow[t]{2}{*}{ Indoor hobby/sport } & $21(27)$ & I want to get back to playing guitar \\
\hline & & $\begin{array}{l}\text { I want to get back to cooking for my family and for } \\
\text { social events }\end{array}$ \\
\hline \multirow[t]{2}{*}{ Outdoor hobby/sport } & $20(26)$ & I would like to play wheelchair rugby \\
\hline & & I want to be able to go fishing again \\
\hline \multirow[t]{2}{*}{ Community access } & $19(24)$ & $\begin{array}{l}\text { I want to get back to socialising and going out with } \\
\text { my friends }\end{array}$ \\
\hline & & $\begin{array}{l}\text { I want to get out into the community to art galleries, } \\
\text { museums, dressage competitions etc }\end{array}$ \\
\hline $\begin{array}{l}\text { Technology/ } \\
\text { communication }\end{array}$ & $18(23)$ & $\begin{array}{l}\text { I want to be able to use my laptop for emails and } \\
\text { Skype }\end{array}$ \\
\hline
\end{tabular}

I want to be able to operate a computer to do some photo editing 
Table 4. Multidisciplinary Goal Attainment Measure (MGAM) scores

\begin{tabular}{lrrr}
\hline \multicolumn{1}{l}{ Total MGAM performance score } & Pre & Post & Change \\
Range & & & $1.2-9.3$ \\
Mean (SD) & $0-4.7$ & $3-9.3$ & $5.26(1.74)$ \\
Standard error mean & $2.12(1.36)$ & $7.38(1.33)$ & 0.35 \\
Total MGAM satisfaction score & 0.27 & 0.27 & $2.6-9.3$ \\
Range & & & $5.83(2.24)$ \\
Mean (SD) & $0-6.3$ & $3.4-10$ & 0.45 \\
Standard error mean & $2.41(2.01)$ & $8.23(1.41)$ & 0.28 \\
\end{tabular}

\section{DISCUSSION}

The present study aimed to explore the nature of leisure therapy goals in inpatient SCI rehabilitation, evaluate the provision of leisure therapy services through an exploration of goal attainment, and to further explore the sensitivity and applicability of the MGAM to the inpatient multidisciplinary setting.

Our findings suggest people with a SCI involved in inpatient rehabilitation identify a range of leisure-specific goals that are not merely sport-related. Goals spanned indoor hobbies and sports, outdoor hobbies and sports, community access and technology and communication. Individuals of both genders and across all ages identified goals crossing these domains. The findings support the notion that people engage or wish to engage in a diversity of activities that can include crafts, sports and gardening (O'Brien et al, 2008; Martin Ginis et al, 2010). This finding expands on the current literature that tends to focus on sport and exercise, referred to as leisure time physical activity (Carpenter et al, 2007). Indeed, the diversity of leisure needs may be particularly important for people with SCI as certain leisure activities may no longer be viable or desired because of functional limitations (Loy et al, 2003; Gassaway et al, 2011). The success of rehabilitation in this area is contingent upon setting goals that are relevant to the leisure needs of the patient (Barclay et al, 2011).

The present study found that participants rated both goal performance and goal satisfaction significantly higher following leisure therapy services. While there was no control group in the current study to act as a comparison, the findings suggest that individuals are not only performing significantly better on their leisure-specific goals, but they are also more satisfied with their progress. The slightly higher change in goal satisfaction highlights the importance of client perceptions and their adjustment following injury, and reinforces that goal attainment is more than just skill development. Active engagement in life and satisfaction with leisure have previously been associated with improved subjective wellbeing following SCI (Loy et al, 2003).

Exposure to community settings and leisure activities has previously been found to enhance outcomes for people at rehabilitation discharge and at 1 year post injury. Some of these outcomes include higher social integration, occupation and mobility, increased life satisfaction, more stable accommodation, less rehospitalisation and less secondary complications (Cahow et al, 2012).

Patient specific measurement instruments such as the COPM and the MGAM tend to be more sensitive to change than traditional measures of function (Law et al, 1990; Donnelly et al, 2004; Gustaffson et al, 2012; Kendall and Wallace, 2016). The present study supports this notion. Law et al (2014) reported that change scores over 2.5 represented a clinically significant change on the COPM. Therefore, the change scores of 5.26 and 5.83 on goal performance and satisfaction respectively for the MGAM change. This supports both the feasibility strongly suggest a clinically significant and sensitivity of the MGAM in this setting. In addition, there were no differences across demographics in terms of initial and final scores. This finding reinforces the assumption that leisure therapy is for everyone and not just for young people or those wanting to pursue sporting interests. O'Brien et al (2008) found that participants' decisions around leisure resumption are not solely based on having a SCI but are also related to other factors, such as individual preferences, relationships with partners, families and friends, as well as the place of the individual in the life course. The individualised nature of leisure therapy combined with the use of client-centred outcome measures allows the individual to identify and measure their areas of difficulty or their desired goals.

Leisure therapy is more than a recreation programme aimed at the group. It is individualised and able to meet participants' own needs. Leisure therapists assist individuals and families to acquire necessary skills and resources to enable safe and rewarding leisure experiences (Cahow et al, 2012). Participating in a variety and balance of activities and roles including leisure activities, enables people with SCI to structure their time use, express themselves and find meaning in their lives (Harvey and Pentland, 2010).

Clearly, engagement in leisure pursuits is linked with the ICF concept of participation. Barclay and colleagues (2015) highlight that participation is not merely related to the number of hours spent in activities but also the meaning, quality of participation and levels of engagement.

\section{Limitations}

The present study is limited by the lack of a control group, the fact that leisure therapy treatment was not standardised, and the relatively small sample size. Furthermore, the study is limited in scope to the inpatient setting. Further research is required to examine whether goal attainment scores are maintained over time;

\section{'Leisure-specific goal attainment improved significantly after the provision of leisure therapy in terms of both goal performance and goal satisfaction.'}




\section{'The individualised nature of leisure therapy combined with the use of client-centred outcome measures allows the individual to identify and measure their areas of difficulty or their desired goals.'}

to explore the impact of leisure therapy on psychosocial adjustment to injury; and to determine whether provision of leisure therapy services changes the nature of the rehabilitation goals set. Indeed, the next step would be to measure the long-term effects of leisure therapy interventions on participation in leisure activities in the community.

\section{CONCLUSION}

The present study supports the valuable role of leisure therapists in the provision of holistic rehabilitation for people with SCI. Individuals identify a range of leisurespecific goals following SCI including both indoor and outdoor leisure pursuits, community access and technology and communication.

The present study revealed that leisure-specific goal attainment improved significantly after the provision of leisure therapy in terms of both goal performance and goal satisfaction. The lack of differences in goal attainment across age, gender, level and completeness of injury suggest that all people with SCI may benefit from leisure therapy services. The MGAM was a valuable tool for measuring goal attainment in inpatient rehabilitation. IJTR

Barclay L, Callaway L, McDonald R, Farnworth L, Brown T, Broom L (2011) Time use following spinal cord injury: an examination of the literature. Br J Occup Ther 74(12): 573-80. doi: 10.4276/030802211X13232584581452

Barclay L, McDonald R, Lentin P, Bourke-Taylor H (2015) Facilitators and barriers to social and community participation following spinal cord injury. Aust Occup Ther J 63(1): 19-28. doi: 10.1111/1440-1630.12241

Barker RN, Kendall MD, Amsters DI, Pershouse KJ, Haines TP (2009) The relationship between quality of life and disability across the lifespan for people with spinal cord injury. Spinal Cord 27(2): 149-55. doi: 10.1038/sc.2008.82

Byrnes M, Beilby J, Ray P, McLennan R, Ker J, Schug S (2012) Patient-focused goal planning process and outcome after spinal cord injury rehabilitation: quantitative and qualitative audit. Clin Rehabil 26(12): 1141-49. doi: 10.1177/0269215512442669

Cahow C, Gassaway J, Rider C et al (2012) Relationship of therapeutic recreation inpatient rehabilitation interventions and patient characteristics to outcomes following spinal cord injury: The SCIRehab Project. J Spinal Cord Med 35(6): 547-48. doi: 10.1179/2045772312Y.0000000066

Carpenter C, Forwell SJ, Jongbloed LE, Backman CL (2007) Community participation after spinal cord injury. Arch Phys Med Rehabil 88(4): 427-33. doi: 10.1016/j.apmr.2006.12.043

Chun S, Lee Y (2010) The role of leisure in the experience of posttraumatic growth for people with spinal cord injury. J Leis Res 42(3): 393-415

Donnelly C (2004) Client-centred assessment and the identification of meaningful treatment goals for individuals with spinal cord injury. Spinal Cord 42(5): 302-7. doi: 10.1038/sj.sc.3101589 10.1038/sj.sc.3101589

Gassaway J, Dijkers M, Rider C, Edens K, Cahow C, Joyce J (2011) The SCIRehab project: therapeutic recreation treatment time during inpatient rehabilitation. J Spinal Cord Med 34(2): 176-85 doi: 10.1179/107902611X12971826988138

GNU Project (2015) GNU PSPP (Version 0.8.5) Free Software Foundation. https://www.gnu.org/ software/pspp/ (accessed 24 May 2017)

Gustafsson L, Mitchell G, Fleming J, Price G (2012) Clinical utility of the Canadian Occupational Performance Measure in spinal cord injury rehabilitation. Br J Occup Ther 75(7): 337-43. doi: 10.4276/030802212X13418284515910

Harvey AS, Pentland W (2010) What do people do? in: Christiansen $\mathrm{CH}$, Townsend EA, eds. Introduction to Occupation: The Art and Science of Living. Penhall, New Jersey, NY

Juniper D (2003) Leisure counselling in stress management. Work Study 52(1): 7-12. doi: 10.1108/00438020310458679

Kendall MB, Wallace MA (2016) Measuring goal attainment within a community-based multidisciplinary rehabilitation setting for people with spinal cord injury. Edorium J Disabil Rehabil 2: 43-52. doi:10.5348/D05-2016-10-OA-6

Law M, Baptiste S, McColl M, Opzoomer A, Polatajko H, Pollock N (1990) The Canadian Occupational Performance Measure: an outcome measure for occupational therapy. Can J Occup Ther 57(2) 82-7. doi: 10.1177/000841749005700207

Law M, Baptiste S, Carswell A, McColl MA, Polatajko H, Pollock N (2014) Canadian Occupational Performance Measure. 5th edn. CAOT Publications ACE, Ottawa

Lee Y, McCormick B (2004) Subjective well-being of people with spinal cord injury: does leisure contribute? J Rehabil 70(3): 5-12

Loy DP, Dattilo J, Kleiber D (2003) Exploring the influence of leisure on adjustment: development of the leisure and spinal cord injury adjustment model. Leis Sci 25(2-3): 231-55. doi: 10.1080/01490400306565

Lundstrom U, Lilja M, Petersson I, Lexell J, Isaksson G (2014) Leisure repertoire among persons with a spinal cord injury: interests, performance and well-being. J Spinal Cord Med 37(2): 186-92. doi: 10.1179/2045772313Y.0000000103

Martin Ginis KA, Arbour-Nicitopoulos KP, Latimer AE et al (2010) Leisure time physical activity in a population-based sample of people with spinal cord injury part ii: activity types, intensities and durations. Arch Phys Med Rehabil 91(5): 729-33. doi: 10.1016/j.apmr.2009.12.028

O'Brien A, Renwick R, Yoshida K (2008) Leisure participation for individuals living with acquired spinal cord injury. Int J Rehabil Res 31(3): 225-30. doi: 10.1097/MRR.0b013e3282fb7d13

Queensland Leisure Therapy Network (2015) What is leisure therapy? https://www.health.qld.gov. au/qscis/html/leisure.asp (accessed 24 May 2017)

Rubinelli S, Glässel A, Brach M (2016) From the person's perspective: perceived problems in functioning among individuals with spinal cord injury in Switzerland. J Rehabil Med 48(2): 235 43. doi: 10.2340/16501977-2060

Schönherr MC, Groothoff JW, Mulder GA. Eisma WH (2005) Participation and satisfaction after spinal cord injury: results of a vocational and leisure outcome study. Spinal Cord 43(4): 241-48. doi: 10.1038/sj.sc.3101683

Semerjian TZ, Montague SM, Dominiguez JF, Davidian AM, De Leon RD (2005) Enhancement of quality of life and body satisfaction through the use of adapted exercise devices for individuals with spinal cord injuries. Top Spinal Cord Inj Rehabil 11(2): 95-108. doi: 10.1310/BXE2MTKU-YL15-429A

Stephens C, Neil R, Smith P (2012) The perceived benefits and barriers of sport in spinal cord injured individuals: A qualitative study. Disabil Rehabil 34(24): 2061-70. doi: 10.3109/09638288.2012.669020

Stevens A, Beurskens A, Koke A, Van Der Weijden T (2013) The use of patient-specific measurement instruments in the process of goal-setting: a systematic review of available instruments and their feasibility. Clin Rehabil 27(11): 1005-19. doi: 10.1177/0269215513490178

Williams TL, Smith B, Papathomas A (2014) The barriers, benefits and facilitators of leisure time physical activity among people with spinal cord injury: a meta-synthesis of qualitative findings. Health Psychol Rev 8(4): 404-25. doi: 10.1080/17437199.2014.898406

Witt J, Campbell M, Witt P (1981) A Manual of Therapeutic Group Activities for Leisure Education. Hawkins \& Associates, New York, NY

World Health Organization (2001) International Classification of Functioning, Disability and Health (ICF). WHO, Geneva 